\title{
Do physicians discuss end-of-life decisions with family members? A mortality follow-back study
}

Maarten Vermorgen ${ }^{a *}$; Aline De Vleminck ; Luc Deliens ${ }^{a, b}$; Dirk Houttekier ${ }^{a}$; Nele Spruytte ${ }^{c}$; Chantal Van Audenhovec; Joachim Cohen ${ }^{\mathrm{a}}$; Kenneth Chambaere ${ }^{\mathrm{a}}$

\footnotetext{
a End-of-life Care Research Group, Vrije Universiteit Brussel (VUB) \& Ghent University, Brussels, Belgium

${ }^{b}$ Department of Medical Oncology, Ghent University Hospital, Ghent, Belgium

${ }^{c}$ LUCAS Center for Care Research and Consultancy, University of Leuven, Leuven, Belgium
}

\section{*Corresponding author at:}

Maarten Vermorgen, M.Sc.

End-of-Life Care Research Group

Vrije Universiteit Brussel (VUB) \& Ghent University

Koningin Astridlaan 49, 1780 Wemmel, Belgium

E-mail: maarten.vermorgen@vub.be

Tel: +32 24548037

\section{Contact information of other authors:}

Aline De Vleminck, PhD: aline.de.vleminck@vub.be

Luc Deliens, PhD: luc.deliens@vub.be

Dirk Houttekier, PhD: dirk.houttekier@vub.ac.be

Nele Spruytte,PhD: nele.spruytte@kuleuven.be or nele.spruytte@som.be

Chantal Van Audenhove, PhD: chantal.vanaudenhove@kuleuven.be

Joachim Cohen, PhD: joachim.cohen@vub.be

Kenneth Chambaere, PhD: kenneth.chambaere@vub.be

Keywords: end of life; informal caregivers; family caregivers; palliative care; decision-making 


\begin{abstract}
:
Objective: Deaths from chronic illness are often preceded by a potentially life-shortening end-of-life decision (ELD). Involving family in these ELDs may have psychosocial benefits for them and the dying person. This study aims to examine how often ELDs are discussed with relatives of the dying person and which characteristics determine their involvement in those ELDs.
\end{abstract}

Methods: A questionnaire survey was conducted in 2013 among physicians attending a large, stratified and representative sample of deaths $(n=6,188)$ in Flanders.

Results: In $72.3 \%$ of ELDs preceding death, family of the dying person were involved. Discussion of an ELD with family members was more likely when the decision was also discussed with the dying person, the ELD was made with the explicit intention to shorten life, specialized palliative care was provided or death occurred in an ICU.

Conclusions: Involving family in end-of-life decision making appears to be related to the type of formal care services involved, communication with the dying person and the motives behind the decision.

Practice implications: Our findings suggest a need to further expand a palliative care approach with a focus on both the dying person and their family within and across a variety of health care services. 


\section{Introduction}

An increasing number of people are confronted with a relative who is dying from a chronic life-limiting disease such as cancer, dementia or cardiovascular disease [1]. These deaths are often, and increasingly, preceded by potentially life-shortening medical end-of-life decisions (ELDs) [2-9], including non-treatment decisions (withholding or withdrawing medical treatment) and increasing drug administration to relieve pain and other symptoms, or less common procedures such as physician-assisted suicide and euthanasia (defined as 'the act, undertaken by a third party, which intentionally ends the life of a person at his or her request' [10]). How health care providers deal with the views and concerns of relatives of the person who is dying during the decision-making process is an important determinant of high-quality end-of-life care [11], and informing them about the consequences of a decision, thereby preparing them for the person's death, is the least that can be expected from physicians when such a decision is being made.

While research on the incidence of end-of-life practices and the decision-making process preceding them has mostly focused on physicians and patients, there is a scarcity of empirical studies on how family members are involved in ELDs, especially in situations where the dying person has retained decision-making capacity. However, according to the World Health Organization, palliative care should aim to enhance the quality of life of both patients and their relatives who are confronted with the problems associated with lifethreatening illness through the prevention and relief of physical, psychosocial and existential suffering [12]. From this perspective, it is considered as good practice to involve relatives of the people who are dying in the decision-making process, irrespective of the capacity of those dying people and without disregarding the law or denying them their right 
to decide for themselves. As demonstrated by a structured review about advance care planning in primary health care [13], the process of developing advance directives may promote conversations about ELDs between ill persons, their family and physicians at an early stage. However, according to data collected in Belgium and the Netherlands, only $8 \%$ of the persons dying from a non-sudden illness in these regions have an advance directive, with Belgians being twice less likely to have one [14].

Shared decision-making and effective and timely communication with both the dying person and their relatives have been shown to be important in providing patients and family caregivers with an optimal end-of-life experience [15]. Early and proactive communication with relatives of the dying person about the end of life can positively influence their psychosocial well-being and the bereavement process as well [16-18]. Studies show that many people also prefer their family to be involved in medical decisions made at the end of life, regardless of whether they still have decision-making capacity [19-22]. Additionaly, being involved in medical decision-making may help family members to understand and accept the treatment choices of the physicians and of the person who is dying $[23,24]$.

In 2002, Belgium adopted federal laws on patient rights, palliative care and euthanasia, making it one of the few countries - alongside the Netherlands, Luxembourg and Colombia in which euthanasia is legal. These pieces of legislation provide a framework for increased patient autonomy in end-of-life care. Previous research on ELDs in Belgium has shown that Flemish physicians were increasingly discussing ELDs with relatives, whether the dying person possessed capacity (71\% in 2001 vs. $60 \%$ in 1998) or was lacking it (77\% in 2001 vs. $55 \%$ in 1998) [25]. In a comparative study between Belgium and five other European 
countries, only in the Netherlands was family more frequently involved in decisions regarding the end of life [26]. In 2007, however, these rates had dropped again [27]. One study notably showed that less than half of patients with lung cancer who had lost decisionmaking capacity had had their ELD discussed by their relatives and the physician [20]. Currently, little is known about the clinical and patient characteristics that are associated with such involvement in ELDs.

Therefore, the aim of this study is to answer the following research questions: a) how often do physicians discuss ELDs with the relatives of the person who is dying in current medical practice in Flanders? b) is such involvement in ELDs associated with characteristics concerning the patient, type of ELD (i.e. patient involvement, limitation of treatment vs. active drug administration, and the intention underlying the decision) or other care characteristics?

\section{Methods}

\subsection{Study design and study sample}

This study reports findings from a postmortem questionnaire survey of physicians attending a representative sample of deaths in Flanders, asking them to report on the end-of-life decisions they made relating to those deaths. The stratified random sample was drawn by the Flemish Agency for Care and Health from death certificates of Belgian residents aged one year or older between 1 January and 30 June 2013. Firstly, all death certificates were divided into three strata based on the underlying cause of death as indicated on the death 
certificate. Cases were then sampled with different sampling fractions for each stratum to include not only more cases where an ELD was made, but also a sufficient amount of uncommon ELDs such as euthanasia. In the first stratum, all deaths for which euthanasia was mentioned on the death certificate were sampled. In the second stratum, one third of all cancer deaths were sampled. In the third stratum, one in six deaths resulting from any other cause were sampled. The sampling fractions reflected the likelihood of an ELD as observed in previous surveys [28]. This procedure resulted in a sample of 6,188 deaths. Each certifying physician was sent a five-page questionnaire for a maximum of five cases, with at most three reminders in cases of nonresponse. A lawyer acted as intermediary between responding physicians, researchers, and the administration authorities for the death certificates in this mailing procedure to guarantee that completed questionnaires could never be linked to a particular decedent or physician. This lawyer also de-identified the death certificates received from the administrative authorities to the corresponding completed questionnaires received from the physicians and further anonymized the databases. After data collection, a one-page questionnaire was mailed to all non-responding physicians asking for their reasons for not participating.

\subsection{Questionnaire}

We used a slightly adapted version of a questionnaire that has been repeatedly validated in studies in the Netherlands [5], Flanders [28] and other countries [26]. It first asked whether death had been sudden and unexpected and whether the attending physician's first contact with the patient had been after death. If both questions were answered negatively (and hence end-of-life decision-making before death could not be precluded), physicians were asked whether they had withheld or withdrawn medical treatment taking into account or 
explicitly intending the shortening of the individual's life (non-treatment decision), had intensified the alleviation of pain and other symptoms with possible shortening of life, or had administered, supplied, or prescribed drugs with the explicit intention of hastening death (physician-assisted death). The latter act was classified as either euthanasia or physician-assisted suicide (depending respectively on whether the physician or the patient had administered the drugs) if it was done at the explicit request of the individual; without such an explicit request, the act was classified as administering life-ending drugs without explicit request. If more than one end-of-life decision was made, the one with the most explicit life-shortening intention was considered the most important, and if there was more than one act with a similar life-shortening intention, the administering of drugs was regarded as prevailing over the withholding or withdrawal of treatment. Questions about the decision-making process preceding the most important end-of-life decision and about care characteristics followed. More specifically, physicians were asked about the patient's capacity at the time of the ELD, patient and family involvement in the decision-making process, and the provision of specialized palliative care. Whether the ELD was discussed with family was determined by posing the question 'did you or another physician discuss the possible life-shortening effect of the decision with others before deciding to take the aforementioned course of action?', with the possible answer being 'yes, with the partner and/or family of the patient'.

Data on the individual's sex, age, marital status, education and underlying cause of death were available from the individually linked death certificate, while place of death was determined by a question in the questionnaire. 


\subsection{Statistical analysis}

The response sample was first corrected for disproportionate stratification (by weighting each stratum to make the proportion in the response sample identical to the proportion in all deaths) and adjusted to be representative of all deaths in Flanders in the first half of 2013 in terms of age, sex and province, place, and cause of death (adjustments were needed for place of death). After this weighting procedure there were no significant differences between response sample and all deaths in any of these variables. Persons younger than 18 were excluded from our analyses as the process of involving their family (often their parents) in discussions about medical decisions differs profoundly from the involvement of an adult's relatives.

All statistical analyses were performed with complex sample functions in SPSS version 24.0 to account for the complex stratification procedure used for our sample. Bivariate crosstabulations were calculated to compare associations between family involvement in ELDs and different patient, care, and ELD characteristics. Variables that are bivariately associated with family involvement in ELDs are included, along with a set of core variables (sex, age, main diagnosis and place of death) in a multivariate logistic regression model. Statistical significance was set at $p<.05$.

\subsection{Ethics}

The mailing and anonymity procedures were approved by the Ethical Review Board of the University Hospital of the Vrije Universiteit Brussel (approval number B.U.N. 
143201316288), the Belgian National Disciplinary Board of Physicians, and the Belgian Federal Privacy Commission. The funding source had no role in this study.

\section{Results}

Response rate was $60.6 \%$, resulting in data from 3,751 deaths. In $47.6 \%$ of these cases $(N=$ 1,787), an end-of-life decision (ELD) had preceded death of a person aged 18 or older.

\subsection{Cohort description}

Of the individuals who died, $58.1 \%$ were aged 80 or older, $34.7 \%$ had cancer as the main diagnosis, and $79.3 \%$ died in a place other than home. More than half $(55.0 \%)$ received care from palliative care services at the end of their lives. In $59.5 \%$ of cases, capacity was no longer present when the most important ELD was being made.

\subsection{Family involvement according to clinical and patient characteristics}

Family members of the person who was dying were involved in $72.3 \%$ of all ELDs (Table 1 ).

ELDs were most frequently discussed with relatives when the person died in an intensive care unit (ICU; 85.1\%), received specialized palliative care $(75.9 \%)$, was married $(77.2 \%)$, did not have a higher education degree (71.5\%-78.1\%), and when the ELD was also discussed with them (76.6\%). In contrast, rates of family involvement did not differ by sex, age and main diagnosis. Further analysis showed that in $11.1 \%$ of ELDs made when the dying person still had capacity, the decision was discussed with their family but not with them. 
Table 1. Clinical and patient characteristics and their relation to family involvement across all ELDs

\begin{tabular}{|c|c|c|c|c|}
\hline & Characteristics & Weighted & $\begin{array}{l}\text { Family } \\
\text { involved }\end{array}$ & $\begin{array}{c}\text { Pearson } \\
\text { chi- }\end{array}$ \\
\hline & & $\mathrm{N}(\%)$ & $\%$ & \\
\hline Total & & $1,787(100)$ & 72.3 & \\
\hline Sex & Male & $849(47.6)$ & 72.4 & $p=.96$ \\
\hline & Female & 935 (52.4) & 72.2 & \\
\hline Age & $18-64$ & 239 (13.4) & 68.3 & $p=.129$ \\
\hline & $65-79$ & $509(28.5)$ & 75.4 & \\
\hline & $80+$ & $1,036(58.1)$ & 71.7 & \\
\hline Marital status & Unmarried & $132(7.4)$ & $54.5^{*}$ & $\mathrm{p}<.001$ \\
\hline & Married & $782(43.8)$ & $77.2^{*}$ & \\
\hline & Widowed & $749(42.0)$ & 70.7 & \\
\hline & Divorced & $120(6.7)$ & 70.0 & \\
\hline Education & None or primary school & $447(40.5)$ & 71.5 & $\mathrm{p}=.032$ \\
\hline & Secondary school, not graduated & $294(26.6)$ & 78.1 & \\
\hline & Secondary school, graduated & $274(24.8)$ & 72.0 & \\
\hline & Higher education (college/university) & $89(8.1)$ & 61.7 & \\
\hline Main diagnosis & Cardiovascular disease & $270(15.2)$ & 76.2 & $p=.27$ \\
\hline & Cancer & $620(34.7)$ & 71.1 & \\
\hline & Respiratory disease & $193(10.8)$ & 76.5 & \\
\hline & Neurological disease & $104(5.8)$ & 77.3 & \\
\hline & Cerebrovascular accident (CVA) & $159(8.9)$ & 67.8 & \\
\hline & Other & $437(24.5)$ & 70.3 & \\
\hline Place of death & Home & $368(20.7)$ & 69.3 & $\mathrm{p}<.001$ \\
\hline & Nursing home & 495 (27.9) & 70.6 & \\
\hline & Hospital & & & \\
\hline & Emergency room & $19(1.1)$ & 41.9 & \\
\hline & ICU & $243(13.7)$ & $85.1 *$ & \\
\hline & Palliative care unit & $97(5.5)$ & 64.1 & \\
\hline & Other hospital ward & $552(31.1)$ & 73.3 & \\
\hline Palliative care services & Yes & $979(55.0)$ & 75.9 & $p<.001$ \\
\hline involved at end of life & No & $800(45.0)$ & 67.8 & \\
\hline Patient having mental & Yes & $677(40.5)$ & 73.6 & $p=.36$ \\
\hline capacity at time of ELD & No & $994(59.5)$ & 71.5 & \\
\hline ELD discussed with & Yes & $602(35.7)$ & 76.6 & $p=.004$ \\
\hline patient & No & $1,086(64.3)$ & 69.8 & \\
\hline
\end{tabular}

* denotes that a specific category differs significantly from the others for a variable with more than two categories (through post-hoc analysis)

Missing values of: sex $=0.1 \%$; age $=0.1 \%$; marital status $=0.2 \%$; education $=38.2 \%$; main diagnosis $=0.2 \%$; place of death $=0.7 \%$; palliative care services involved at end of life $=$ 
$0.5 \%$; patient capacity at time of ELD $=6.5 \%$; ELD discussed with patient $=5.6 \%$; ELD

discussed with relative $=6.2 \%$

\subsection{Family involvement according to type of ELD}

Family involvement in discussions about ELDs varied according to the type of medical decision (Table 2). Our results indicate that ELDs were less often discussed with relatives when they were taken without an explicit intention to hasten death. Rates of family involvement in these cases ranged from $64.2 \%$ (non-treatment decision) to $66.6 \%$ (alleviating pain and symptoms). In contrast, family involvement rates varied from $76.8 \%$ (alleviation of pain and symptoms) to $81.3 \%$ (euthanasia or assisted suicide) when an intention to shorten life was present.

Table 2. Prevalence of family involvement in different types of ELDs

\begin{tabular}{|c|c|c|}
\hline Type of ELD & $\begin{array}{c}\text { Weighted } \\
\text { sample } \\
\mathrm{N}(\%)\end{array}$ & $\begin{array}{c}\text { ELD discussed } \\
\text { with family } \\
\% \\
\end{array}$ \\
\hline \multicolumn{3}{|l|}{ Non-treatment decision } \\
\hline Life-shortening not intended & $235(13.1 \%)$ & $64.2 \%$ \\
\hline Life-shortening intended & $411(23.0 \%)$ & $79.8 \%$ \\
\hline \multicolumn{3}{|l|}{ Alleviation of pain and symptoms } \\
\hline Life-shortening not intended & $766(42.8 \%)$ & $66.6 \%$ \\
\hline Llife-shortening co-intended & $138(7.7 \%)$ & $76.8 \%$ \\
\hline \multicolumn{3}{|l|}{ Physician-assisted death } \\
\hline Euthanasia or assisted suicide & $173(9.7 \%)$ & $81.3 \%$ \\
\hline Life-ending actions without explicit patient request & $65(3.6 \%)$ & $78.5 \%$ \\
\hline Chi-square test & & $p<.001$ \\
\hline
\end{tabular}

The education variable was excluded from our model because of the high number of missing values (38.2\%), although its inclusion would have resulted in similar outcomes. 


\subsection{Factors associated with family involvement in ELDs}

The results of the multivariable logistic regression analysis are displayed in Table 3. ELDs were more likely to be discussed with relatives when the ELD was taken with the explicit intention of shortening life (such ELDs include all physician-assisted deaths and some of the decisions to stop or not to begin medical treatment or to administer pain-relieving drugs; $\mathrm{OR}=1.79,95 \% \mathrm{Cl}=1.38-2.31)$. ELDs were less likely to be discussed with relatives if patients were widowed $(\mathrm{OR}=0.72,95 \% \mathrm{Cl}=0.52-0.98)$ or had never been married $(\mathrm{OR}=0.42,95 \%$ $\mathrm{Cl}=0.27-0.64)$ than when they were married. When death took place in an ICU, individuals were more likely to have their family involved in their ELD than when dying at home $(O R=$ $3.15,95 \% \mathrm{Cl}=1.83-5.39)$. Compared with death in an ICU, people who died in any other location were less likely to have their ELD discussed with their family (ORs ranging from 0.12-0.43, 95\% Cls ranging from 0.04-0.72). Those who received end-of-life care from specialized palliative care services $(\mathrm{OR}=1.79,95 \% \mathrm{Cl}=1.38-2.33)$ and those who were involved in the decision-making process $(\mathrm{OR}=1.33,95 \% \mathrm{Cl}=1.01-1.75)$ were also more likely to have their family involved in their ELDs.

Table 3. Logistic regression analysis: patient, care, and ELD characteristics associated with family involvement

\begin{tabular}{|c|c|c|}
\hline \multicolumn{2}{|c|}{ Characteristics } & \multirow{2}{*}{$\begin{array}{c}\text { Odds ratio }(95 \% \mathrm{Cl}) \\
0.99(0.74-1.31)\end{array}$} \\
\hline $\begin{array}{l}\text { Administration of drugs vs. } \\
\text { non-treatment }\end{array}$ & Yes (vs no) & \\
\hline $\begin{array}{l}\text { Life-shortening intention by } \\
\text { the physician }\end{array}$ & Yes (vs no) & $1.79(1.38-2.31)$ \\
\hline Sex & Men (ref = women) & $0.86(0.66-1.12)$ \\
\hline \multirow[t]{3}{*}{ Age } & $18-64$ & $0.72(0.49-1.06)$ \\
\hline & $65-79$ & $1.04(0.76-1.42)$ \\
\hline & $80+$ & Ref \\
\hline \multirow[t]{2}{*}{ Marital status } & Married & Ref \\
\hline & Unmarried & $0.42(0.27-0.64)$ \\
\hline
\end{tabular}




\begin{tabular}{llc}
\hline & Widowed & $\mathbf{0 . 7 2}(\mathbf{0 . 5 2}-\mathbf{0 . 9 8})$ \\
Main diagnosis & Divorced & $0.77(0.48-1.24)$ \\
& Cancer & Ref \\
& Cardiovascular disease & $1.27(0.83-1.95)$ \\
& Respiratory disease & $1.52(0.93-2.49)$ \\
& Neurological disease & $1.56(0.88-2.75)$ \\
& CVA & $0.95(0.56-1.60)$ \\
Place of Death & Other & $1.02(0.71-1.47)$ \\
& Home & Ref \\
& Nursing home & $1.24(0.88-1.76)$ \\
& Emergency room & $0.37(0.12-1.17)$ \\
Palliative care services & ICU & $\mathbf{3 . 1 5}(\mathbf{1 . 8 3 - 5 . 3 9 )}$ \\
involved at end of life & Palliative care unit & $0.87(0.53-1.430)$ \\
Patient involvement & Other hospital ward & $1.34(0.96-1.86)$ \\
Ref $=$ reference category, $\mathrm{Cl}=$ confidence interval. & $\mathbf{1 . 7 9}(\mathbf{1 . 3 8 - 2 . 3 3 )}$ \\
\hline
\end{tabular}

\section{Discussion and conclusion}

\subsection{Discussion}

This study shows that relatives of more than a quarter of all people who died after an ELD (27.7\%) were not involved in a conversation about the possible life-shortening effect of the decision and, as such, did not receive information on this matter. The likelihood of family involvement in such a discussion varied according to certain contextual factors: an ELD was more likely to be discussed with a family member when a life-shortening effect was explicitly intended by the physician, when the ELD was also discussed with the dying person, when palliative care services were involved, and when death took place in an ICU. The likelihood of family being involved in such a discussion did not vary with the cause of death.

Our paper is the first to have a systematic and exclusive focus on the discussion of ELDs with relatives of people dying both with and without mental capacity in Flanders. Other 
important strengths are 1) the use of a repeatedly and internationally validated questionnaire using a robust mortality follow-back methodology and 2) a high response rate (61\%) which came from 3) a large and representative sample of deaths.

This study also has some limitations. Firstly, despite the time between death and survey usually being less than two months, physician responses may to some degree have been affected by recall bias. Secondly, although the questionnaire asks about any discussion by the treating physician completing the questionnaire or a colleague physician it is possible that the treating physician is not always aware of ELD discussions with family undertaken by other physicians. However, it can be expected at the least that the treating physician will either have held this discussion themselves or will be aware of one having taken place. Thirdly, our data do not provide contextual information about the manner in which relatives were involved, nor the level of involvement in these discussions, nor at which point in time the conversations were held. We therefore have no information on the direction of information flow between physicians and relatives, which party initiated the talks, nor whether family members had an active voice in the decision-making process. Fourthly, it could be argued that it is a limitation that we have only collected views from physicians, as other healthcare professionals (e.g. nurse practitioners) may also play a role in discussions about ELDs. However, from all involved professional caregivers, physicians are best placed to report on ELDs.

This study has strong external validity, as the response sample is representative of all deaths in Flanders in 2013 with regard to age, sex and cause, specific place and province of death. Despite some differences between health care systems, we believe that our findings from 
Flanders are relevant for other countries as well and could serve as a benchmark. Most countries in the western world have policies that share the palliative and end-of-life care values, goals and guidelines described by international organizations such as WHO. In addition, in recent years the focus of researchers and practitioners has shifted in many countries towards increased advance care planning, shared decision-making and familyorientated end-of-life care.

\subsection{Practical implications}

Our results showed that communication about ELDs between family members of the person who is dying and the treating physician is more likely when the ELD had the intention of shortening life. This intention to shorten life may be the result of extensive discussions with patients and relatives or may equally be the reason the discussion was initiated. It might be that, in the latter case, physicians are not only more likely to provide family members with information to better prepare them for the impending death, but they may also tend to seek confirmation that the decision is justified by talking to them and asking for their perspective. Physicians who are not deliberately seeking the shortening of life, in contrast, may believe that bringing up this possibility is unnecessary, and prefer to avoid a potentially difficult, stressful and time-consuming conversation. However, it is reasonable to ask whether, in the spirit of patient- and family-orientated end-of-life care, it is good practice that physicians refrain from discussing ELDs with relatives at such a crucial time. Evidencebased guidelines have been developed on how health care services and professionals can provide palliative care to family [29]. One of the specific guidelines states that professional care providers need to make sure that the most important family caregiver(s) of an ill person are aware that death is near. Holding respectful conversations in which 
unambiguous and honest information is conveyed may enable family members to understand and accept that the person might be dying and could correct any unrealistic expectations they might have about the outcome of the ELD [23]. In addition, previous research has demonstrated that many family caregivers do not comprehend their relative's illness and its consequences [30]. Nonetheless, as almost everyone who suffers from lungcancer prefers [20], family members are often asked to make important (non)treatment decisions as a substitute when the ill person is incapacitated at the end of life. It is hard to imagine how family members can make a well-informed decision when the implications have not been discussed by health care professionals.

This study also demonstrated that ELDs are more likely to be discussed with family when palliative care services are involved. This finding is in line with a recent study showing that informal caregivers of people with advanced heart failure are often more adequately informed about the person's critical condition when palliative care services are involved [31], maybe because these services are explicitly orientated towards the person who is dying and their family. Our study provides a clear indication that maintaining such a dual approach allows close relatives to receive more information about the situation of the person who is dying, which might also contribute to the quality of end-of-life care as it is experienced. However, the involvement of specialized palliative care is limited in cases where death is preceded by an ELD; our data demonstrate that it was provided only in just over half of these cases. Referral to palliative care services also typically occurs just days or weeks before death [32]. For family members to be reached on a larger scale and to be continuously regarded as care recipients during the illness trajectory, a shift might be needed at multiple levels, firstly towards improving the communication skills of health care 
professionals and instilling a palliative care perspective with a distinct focus on family, and secondly towards integrating a palliative care approach at the organizational level across the range of health care settings.

We observed that the possible life-shortening consequences of an ELD are also more likely to be discussed with relatives when death occurs in an ICU. It is possible that ICUs have more standardized procedures prescribing how to discuss ELDs because such decisions are more common in these settings; however, further research is needed to explore this hypothesis. Alternatively, it could be that the unexpected and emergency nature of many ICU admissions may lead to family members asking for information about decisions and their possible consequences. The higher likelihood of having discussions with family about the ELD is also not necessarily reflective of better communication in ICUs, as previous research has identified numerous barriers to quality communication between physicians and family in an ICU $[33,34]$. Studies have shown that ICU clinicians evaluate the comprehension of ELD-related information in only a quarter of all families [35] and that in some hospitals approximately half of the inquired family members do not understand the diagnosis, prognosis or treatment of a person hospitalized in an ICU [30]. Since our study only assessed whether there was any family involvement in ELDs, further research is needed to look into the exact mechanisms of family participation in decision making in ICUs and other settings. This research might look beyond the physician's view and explore the perceptions of relatives of the dying person about how they were involved and to what extent they would have liked to add to the discussion, e.g. by having the opportunity to ask for clarification, to express their own views or to be considered as equal decision-making partners. 
Lastly, our finding that an ELD is more likely to be discussed with family members when the person who is dying is also involved is in line with a shared decision-making model. This model emphasizes the concept of relational autonomy, acknowledging that individuals are embedded in a broader social environment and cannot be perceived as isolated decisionmakers in medical care [36,37]. Decisions and communication about end-of-life care can be expected to affect the lives of family members as well, both pre- and post-bereavement. A recent study demonstrated that adequate end-of-life communication with family caregivers may be one of the factors that can reduce severe pre-loss grief symptoms which in turn has been shown to be associated with less complicated grief post-bereavement [38]. Follow-up research to explore further the link between end-of-life communication and the effects on bereavement such as complicated grief seems warranted.

\subsection{Conclusion}

Communication with a dying person's relatives can have a beneficial impact on the end-oflife experience and bereavement process of family members. However, this paper demonstrates that in more than a quarter of cases family members do not take part in a conversation about the potential life-shortening effect of medical decisions. Family involvement in these conversations was shown to depend on contextual characteristics such as place of death, referral to a specialized palliative care service, the dying person's own involvement in the discussion and the physician's intention to hasten death. The main recommendation based on these results is that health care services could benefit from the structural implementation of measures aimed at involving family members in discussions about ELDs, with special attention to underserved groups. In order to improve the quality of 
end-of-life care for family members, the communication skills of individual care professionals may need to be enhanced through changes in medical education and training programs. Our results also reveal the importance of promoting a healthcare culture where care professionals consciously take into account the interests of both the person who suffers from an illness and their relatives, which is standard practice in palliative care. Future research is needed to identify interventions that can promote such a holistic perspective within and across different health care services.

\section{Acknowledgements}

The authors would like to thank Jane Ruthven for her language editing and Melanie Schmidt for her contribution on the outline of this article. The authors also want to thank all the physicians who have provided data for this study.

\section{Availability of data and material}

Individual data cannot be made fully available on the internet due to data protection and privacy restrictions that were made under contract with the Flemish Agency for care and health, who collected the data. These restrictions prohibit the research group from sharing the collected data with others to prevent study participants from being identified. Data can be requested from the Flemish Agency (anne.kongs@wvg.vlaanderen.be) after requesting permission from the Privacy Commission (Joris.Ballet@ksz-bcss.fgov.be).

\section{Authors' contributions}


KC, JC and LD collected the data, which were analyzed by MV. The original draft was written by MV, ADV, KC and JC. All authors were involved in the design, review and editing of the paper. The final manuscript was read and approved by all authors.

\section{Funding}

This study, as a part of the INTEGRATE project (a collaboration between the Vrije Universiteit Brussel, Ghent University and University of Leuven), was supported by Flanders Innovation \& Entrepreneurship (Strategic Basic Research SBO-IWT grant no. 140009). The funding agreement ensured the authors' independence in designing the study, interpreting the data, writing, and publishing the report.

\section{Conflict of Interest}

None 


\section{References:}

[1] S. Hall, World Health Organization, eds., Palliative care for older people: better practices, World Health Organization, Regional Office for Europe, Copenhagen, 2011.

[2] J. Bilsen, J. Cohen, K. Chambaere, G. Pousset, B.D. Onwuteaka-Philipsen, F. Mortier, L. Deliens, Medical End-of-Life Practices under the Euthanasia Law in Belgium, N. Engl. J. Med. 361 (2009) 1119-1121.

[3] J. Cohen, K. Chambaere, J. Bilsen, D. Houttekier, F. Mortier, L. Deliens, Influence of the metropolitan environment on end-of-life decisions: A population-based study of end-of-life decision-making in the Brussels metropolitan region and nonmetropolitan Flanders, Health Place. 16 (2010) 784-793.

[4] A. Van der Heide, B.D. Onwuteaka-Philipsen, M.L. Rurup, H.M. Buiting, J.J. van Delden, J.E. Hanssen-de Wolf, A.G. Janssen, H.R.W. Pasman, J.A. Rietjens, C.J. Prins, others, End-of-life practices in the Netherlands under the Euthanasia Act, N. Engl. J. Med. 356 (2007) 1957-1965.

[5] B.D. Onwuteaka-Philipsen, A. Brinkman-Stoppelenburg, C. Penning, G.J. de Jong-Krul, J.J. van Delden, A. van der Heide, Trends in end-of-life practices before and after the enactment of the euthanasia law in the Netherlands from 1990 to 2010: a repeated cross-sectional survey, The Lancet. 380 (2012) 908-915.

[6] C. Seale, End-of-life decisions in the UK involving medical practitioners, Palliat. Med. 23 (2009) 198-204.

[7] S. Pennec, A. Monnier, S. Pontone, R. Aubry, End-of-life medical decisions in France: a death certificate follow-up survey 5 years after the 2005 act of parliament on patients' rights and end of life, BMC Palliat. Care. 11 (2012) 25. doi:10.1186/1472$684 X-11-25$ 
[8] K. Mitchell, G.R. Owens, National survey of medical decisions at end of life made by New Zealand general practitioners, BMJ. 327 (2003) 202-3.

[9] M. Schmid, U. Zellweger, G. Bosshard, M. Bopp, M. Swiss, Medical end-of-life decisions in Switzerland 2001 and 2013: Who is involved and how does the decisionmaking capacity of the patient impact?, Swiss Med. Wkly. (2016). doi:10.4414/smw.2016.14307.

[10] L. Deliens, G. Van der Wal, The euthanasia law in Belgium and the Netherlands, The Lancet. 362 (2003) 1239-1240.

[11] D.K. Heyland, What matters most in end-of-life care: perceptions of seriously ill patients and their family members, Can. Med. Assoc. J. 174 (2006) 627-633.

[12] C. Sepúlveda, A. Marlin, T. Yoshida, A. Ullrich, Palliative care: the World Health Organization's global perspective, J. Pain Symptom Manage. 24 (2002) 91-6.

[13] J.J. Glaudemans, E.P. Moll van Charante, D.L. Willems, Advance care planning in primary care, only for severely ill patients? A structured review, Fam. Pract. 32 (2015) 16-26.

[14] K. Meeussen, L. Van den Block, M. Echteld, N. Bossuyt, J. Bilsen, V. Van Casteren, E. Abarshi, G. Donker, B. Onwuteaka-Philipsen, L. Deliens, Advance Care Planning in Belgium and The Netherlands: A Nationwide Retrospective Study Via Sentinel Networks of General Practitioners, J. Pain Symptom Manage. 42 (2011) 565-577.

[15] J.M. Teno, V.A. Casey, L.C. Welch, S. Edgman-Levitan, Patient-focused, familycentered end-of-life medical care: views of the guidelines and bereaved family members, J. Pain Symptom Manage. 22 (2001) 738-751.

[16] A. Lautrette, M. Darmon, B. Megarbane, L.M. Joly, S. Chevret, C. Adrie, D. Barnoud, G. Bleichner, C. Bruel, G. Choukroun, others, A communication strategy and 
brochure for relatives of patients dying in the ICU, N. Engl. J. Med. 356 (2007) 469478.

[17] K.M. Detering, A.D. Hancock, M.C. Reade, W. Silvester, The impact of advance care planning on end of life care in elderly patients: randomised controlled trial, BMJ. 340 (2010). doi:10.1136/bmj.c1345.

[18] R. Schulz, K. Boerner, J. Klinger, J. Rosen, Preparedness for Death and Adjustment to Bereavement among Caregivers of Recently Placed Nursing Home Residents, J. Palliat. Med. 18 (2015) 127-133.

[19] C. Schäfer, K. Putnik, B. Dietl, P. Leiberich, T.H. Loew, O. Kölbl, Medical decisionmaking of the patient in the context of the family: results of a survey, Support. Care Cancer. 14 (2006) 952-9.

[20] K. Pardon, R. Deschepper, R. Vander Stichele, J.L. Bernheim, F. Mortier, D. Schallier, P. Germonpré, D. Galdermans, W.V. Kerckhoven, L. Deliens, Preferred and Actual Involvement of Advanced Lung Cancer Patients and Their Families in End-of-Life Decision Making: A Multicenter Study in 13 Hospitals in Flanders, Belgium, J. Pain Symptom Manage. 43 (2012) 515-526.

[21] R. Lind, P. Nortvedt, G. Lorem, O. Hevroy, Family involvement in the end-of-life decisions of competent intensive care patients, Nurs. Ethics. 20 (2013) 61-71.

[22] E. Witkamp, M. Droger, R. Janssens, L. van Zuylen, A. van der Heide, How to Deal With Relatives of Patients Dying in the Hospital? Qualitative Content Analysis of Relatives' Experiences, J. Pain Symptom Manage. 52 (2016) 235-242.

[23] G. Caswell, K. Pollock, R. Harwood, D. Porock, Communication between family carers and health professionals about end-of-life care for older people in the acute hospital 
setting: a qualitative study, BMC Palliat. Care. 14 (2015). doi:10.1186/s12904-0150032-0.

[24] C.E. Johnson, R. Singer, M. Masso, M. Sellars, W. Silvester, Palliative care health professionals' experiences of caring for patients with advance care directives, Aust. Health Rev. 39 (2015) 154-9.

[25] J. Bilsen, R. Vander Stichele, B. Broeckaert, F. Mortier, L. Deliens, Changes in medical end-of-life practices during the legalization process of euthanasia in Belgium, Soc. Sci. Med. 65 (2007) 803-8.

[26] A. van der Heide, L. Deliens, K. Faisst, T. Nilstun, M. Norup, E. Paci, G. van der Wal, P.J. van der Maas, End-of-life decision-making in six European countries- descriptive study, The Lancet. 362 (2003) 345-350.

[27] K. Chambaere, J. Bilsen, J. Cohen, B.D. Onwuteaka-Philipsen, F. Mortier, L. Deliens, Trends in Medical End-of-Life Decision Making in Flanders, Belgium 1998-2001-2007, Med. Decis. Making. 31 (2011) 500-510.

[28] K. Chambaere, J. Bilsen, J. Cohen, G. Pousset, B. Onwuteaka-Philipsen, F. Mortier, L. Deliens, A post-mortem survey on end-of-life decisions using a representative sample of death certificates in Flanders, Belgium: research protocol, BMC Public Health. 8 (2008). doi:10.1186/1471-2458-8-299.

[29] P. Hudson, C. Remedios, R. Zordan, K. Thomas, D. Clifton, M. Crewdson, C. Hall, T. Trauer, A. Bolleter, D.M. Clarke, C. Bauld, Guidelines for the Psychosocial and Bereavement Support of Family Caregivers of Palliative Care Patients, J. Palliat. Med. 15 (2012) 696-702. 
[30] E. Azoulay, S. Chevret, G. Leleu, F. Pochard, M. Barboteu, C. Adrie, P. Canoui, J.R. Le Gall, B. Schlemmer, Half the families of intensive care unit patients experience inadequate communication with physicians, Crit. Care Med. 28 (2000) 3044-9.

[31] W. Alonso, J.E. Hupcey, L. Kitko, Caregivers' perceptions of illness severity and end of life service utilization in advanced heart failure, Heart Lung J. Acute Crit. Care. 46 (2017) 35-9.

[32] K. Beernaert, L. Deliens, K. Pardon, L. Van den Block, D. Devroey, K. Chambaere, J. Cohen, What Are Physicians' Reasons for Not Referring People with Life-Limiting Illnesses to Specialist Palliative Care Services? A Nationwide Survey, PLOS ONE. 10 (2015) e0137251. doi:10.1371/journal.pone.0137251.

[33] T.T. Levin, B. Moreno, W. Silvester, D.W. Kissane, End-of-life communication in the intensive care unit, Gen. Hosp. Psychiatry. 32 (2010) 433-442.

[34] M. Visser, L. Deliens, D. Houttekier, Physician-related barriers to communication and patient- and family-centred decision-making towards the end of life in intensive care- a systematic review, Crit. Care. 18 (2014). doi:10.1186/s13054-014-0604-z.

[35] D.B. White, C.H. Braddock, S. Bereknyei, J.R. Curtis, Toward shared decision making at the end of life in intensive care units: opportunities for improvement, Arch. Intern. Med. 167 (2007) 461-467.

[36] Ells, Hunt, Chambers-Evans, Relational autonomy as an essential component of patient-centered care, Int. J. Fem. Approaches Bioeth. 4 (2011) 79-101. doi:10.2979/intjfemappbio.4.2.79.

[37] C.A. Robinson, Advance care planning: re-visioning our ethical approach, CJNR Can. J. Nurs. Res. 43 (2011) 18-37. 
[38] M.K. Nielsen, M.A. Neergaard, A.B. Jensen, P. Vedsted, F. Bro, M.-B. Guldin, Preloss grief in family caregivers during end-of-life cancer care: A nationwide populationbased cohort study, Psychooncology. (2017). doi:10.1002/pon.4416. 